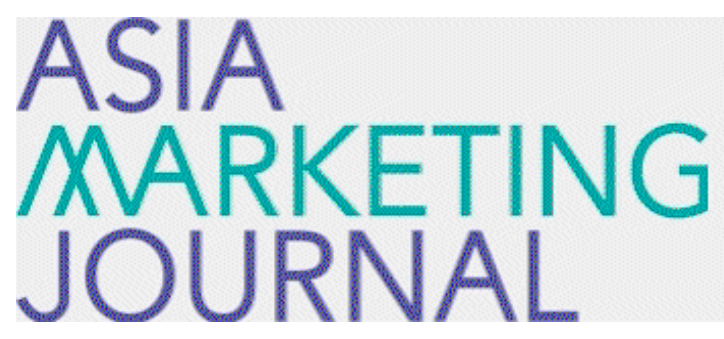

ASIA MARKETING JOURNAL

Volume 16 | Issue 1

Article 5

4-30-2014

\title{
Effects of Emotional Regulation Processes onAdaptive Selling Behavior and Sales Performance
}

Joon Hwan Kim

Sun Gho Lee

Dong Woo Shin

Song

Follow this and additional works at: https://amj.kma.re.kr/journal

Part of the Marketing Commons

\section{Recommended Citation}

Kim, Joon Hwan; Lee, Sun Gho; Shin, Dong Woo; and Song (2014) "Effects of Emotional Regulation Processes onAdaptive Selling Behavior and Sales Performance," Asia Marketing Journal: Vol. 16 : Iss. 1 , Article 5.

Available at: https://doi.org/10.53728/2765-6500.1528

This Article is brought to you for free and open access by Asia Marketing Journal. It has been accepted for inclusion in Asia Marketing Journal by an authorized editor of Asia Marketing Journal. 


\title{
Effects of Emotional Regulation Processes on Adaptive Selling Behavior and Sales Performance*
}

\author{
Joonhwan Kim** \\ Sungho Lee*** \\ Dongwoo Shin \\ Ji-Hee Song*****
}

While the role of emotional antecedents of effective selling behavior would be important, the issue has not been fully addressed in the sales literature. To fill this gap, we conceptualize and empirically examine the relationships among salesperson's emotional regulation processes such as emotional intelligence (EI) and emotional labor (EL), effective selling behavior, and sales performance on the basis of educational, occupational, social psychology literature and marketing literature (e.g., Henning-Thurau, Groth, Paul, and Gremler 2006; Kidwell et al. 2011; Liu et al. 2008; Mayer, Salovey, and Caruso 2008). First, salesperson's EI is defined as his or her capability that enables correct perceptions about emotional situations in sales interactions. The EI is expected to work as psychological resources for different types of EL (i.e., deep acting and surface acting) to be performed by salesperson as emotional expression strategies (e.g., Lie et al. 2008). It is, then, expected that the features of EL selected by the salesperson would lead to different levels of adaptive selling behavior (ASB) and thereby sales performance (Monaghan 2006). Further, given that salesperson's customer orientation (CO) is found to be an important correlate of ASB (Franke and Park 2006), it is expected that CO would moderate the relationship between EL and ASB (Rozell, Pettijohn, and Parker 2004). Hence, this research attempts to shed additional light on emotionally-driven (EL) as well as cognitively-driven (CO) antecedents of ASB (Frank and Park 2006).

The findings of the survey research, done with 336 salespersons in insurance and financial companies, are summarized as follows. First, salespersons with a high level of EI are found to use both deep acting (regulating the emotions themselves) and surface acting (controlling only emotional expressions) in a versatile way, when implementing EL. Second, the more the salesperson performs deep acting, the more he or she shows ASB. It is, then, important for salespersons to use deep acting more frequently

\footnotetext{
* This work was supported by the 2012 Research Fund of the University of Seoul.

** Research Professor, Industry-University Cooperation Foundation, Sungkyul University(kjh715@sungkyul.ac.kr), first author

*** Professor, College of Business Administration, University of Seoul(shlee@uos.ac.kr), corresponding author

**** Associate Professor, College of Business Administration, University of Seoul

***** Associate Professor, College of Business Administration, University of Seoul
} 
in the EL process in order to enhance the quality of interacting with customers through $\mathrm{ASB}$. On the other hand, the salesperson's surface acting did not have a significant relationship with ASB. Moreover, CO was found to moderate the relationship between the salesperson's deep acting and ASB. That is, the context of high CO culture and individual salesperson's deep acting would synergistically make the selling efforts adaptive to customer preferences.

Conceptualizing and empirically verifying the antecedent roles of important emotional constructs such as EI and EL in salesperson's effective selling behavior (ASB) and sales performance is a major theoretical contribution in the sales literature. Managerially, this research provides a deeper understanding on the nature of tasks performed by salespersons in service industries and a few guidelines for managing the sales force. First, sales organizations had better consciously assess EI capacity in the selection and nurturing processes of salespersons, given that EI can efficiently drive EL and the resulting effective selling behavior and performance. Further, the concept of EL could provide a framework to understand the salespersons' emotional experiences in depth. Especially, sales organizations may well think over how to develop deep acting capabilities of their sales representatives. In this direction, the training on deep acting strategies would be an essential task for improving effective selling behavior and performance of salespersons. This kind of training had better incorporate the perspectives of customers such that many customers can actually discern whether salespersons are doing either surface acting or deep acting. Finally, based on the synergistic effects of deep acting and $\mathrm{CO}$ culture, how to build and sustain $\mathrm{CO}$ is always an ever-important task in sales organizations. While the prior sales literature has emphasized the process and structure of highly customer-oriented sales organization, our research not only corroborates the important aspects of customer-oriented sales organization, but also adds the important dimension of competent sales representatives who can resonate with customers by deep acting for sales excellence.

Key words: emotional regulation processes, emotional intelligence, emotional dissonance, emotional labor, adaptive selling behavior, customer orientation, sales performance

\section{Introduction}

Emotional factors involved in the process of interaction between salesmen and customers have been asserted to affect the quality of marketing exchange relationship by many studies (e.g., Bagozzi 1997; Diaz and Ruiz 2002; Smith and
Bolton 2002). Accordingly, many firms have endeavored to provide customers in the exchange process with positive emotional experience by training salespersons to produce an atmosphere of desirable emotions. However, in addition to regarding salespeople as subjects who should get emotional training, we had better improve the understanding on how salespersons' management 
and control of their emotions may affect their selling behavior and performance, which would help firms find the ways of improving the effective selling behavior and sales performance of their salesforce.

Specifically looking into the prior empirical research, only a few studies examined the role of emotion in the context of salesperson behavior. One group of studies found that the high level of efforts by salesman to manage emotions (i.e., emotional labor) positively influenced sales performance and job satisfaction (e.g., Di Mascio 2010; Hennig-Thurau, Groth, Paul, and Gremler 2006: Wong 2005). The other investigated the effect of salesman's emotional intelligence on marketing performance (e.g., Rozell, Pettijohn, and Parker 2004). Considering not only that emotional intelligence and emotional labor constitute a person' emotional regulation processes (e.g., Liu, Prati, Perrewe and Ferris 2008) but also that more research efforts are needed to assess the relationship between emotional factors and effective selling behaviors, it would be important to examine how emotional intelligence and emotional labor are related and they influence salesperson's effective selling behavior and performance.

In other words, it would be worthwhile to understand the relationship between emotional regulation processes and sales performance in an integrated manner with the central constructs of salesperson behavior literature such as the salesperson's adaptive selling behavior (ASB) and customer orientation (CO) (Franke and Park 2006) since the antecedent roles of emotional constructs in effective selling behavior have not been fully investigated. Specifically, we intend to examine how the salesperson's emotional regulation processes are related to $\mathrm{ASB}, \mathrm{CO}$, and sales performance. In the respect that a new research question is examined in an integration with the key constructs of prior studies, our research approach is consistent with that of a few studies (e.g., Kidwell, Hardesty, Murtha, and Sheng 2011; Kim 2010) which delved beyond the direct correlation between emotional factors and marketing performance.

On the basis of educational, occupational, social psychology literature, marketing and management literature (e.g., Henning-Thurau, Groth, Paul, and Gremler 2006; Johnson and Spector 2007; Kidwell et al. 2011; Liu et al. 2008; Mayer, Salovey, and Caruso 2008; Slaski and Cartwright 2002, 2003), we conceptualize to propose and examine the relationships among salesperson's emotional regulation processes, $\mathrm{ASB}, \mathrm{CO}$, and sales performance as follows. First, salesperson's emotional intelligence (EI) is defined as his or her capability that enables correct perceptions about emotional situations in sales interactions. The EI is expected to work as psychological resources for different types of emotional labor (EL) (i.e., deep acting and surface acting) to be performed by salesperson as emotional expression strategies (Lie et al. 2008; McMurrian et al. 2002, 2003). It is, then, expected that the 
features of EL selected by the salesperson would lead to different levels of ASB and thereby sales performance (Monaghan 2006). Further, given that salesperson's $\mathrm{CO}$ is found to be an important correlate of ASB (Franke and Park 2006), it is expected that CO would moderate the relationship between EL and ASB (Rozell, Pettijohn, Parker 2004). ${ }^{1)}$ In other words, construing that $\mathrm{CO}$ has been much examined along with ASB to constitute effective selling behaviors, examining the relationships of $\mathrm{EL}$ and $\mathrm{CO}$ with $\mathrm{ASB}$ may shed additional light on emotionally-driven as well as cognitivelydriven antecedents of ASB (Franke and Park 2006).

In sum, by presenting the detailed paths of salesperson's emotional regulation processes to sales performance from the bird-eye-view of effective selling behavior, we try to gain a theoretical implication on how salesperson's emotional regulation is linked through effective selling behavior to sales performance. Based on our findings, managerial implications can be derived to provide sales managers with how to deal with emotional regulation processes in developing the capabilities of sales representatives. The remainder of the paper is organized as follows. First, we propose the conceptual model and the hypotheses on the relationships among our focal constructs. Then, research method, data characteristics, and results are presented. We conclude by discussing the implications of our findings, limitations, and future research directions.

\section{Conceptualizing the Hypotheses}

\subsection{Emotional Intelligence and Emotional Labor}

Since Goleman (1995) introduced the concept of EI in educational psychology, there have been intensive debates on the definition, measurement, and predictive strength of the construct. Some scholars questioned the validity of the construct (e.g., Landy 2005; Locke 2005; Matthews, Zeidner, and Roberts 2002), while others criticized these attackers for being too strict in their approaches (e.g., Ashkanasy and Daus 2005; Gohm 2004; Oatley 2004). However, Mayer and Salovey (1997) widely accepted the originators of EI but contended that the concept of EI

1) A high $\mathrm{CO}$ reflects a high concern for others, low-pressure selling, and problem-solution selling approaches (Saxe and Weitz 1982), while emotional labor is performed as emotional expression strategies (e.g., Lie et al. 2008). Casually thinking, there might be reciprocal associations between CO and EL. However, to examine how these constructs are conceptually evolved to be related is beyond the scope and context of this research, which warrants separate research efforts. In addition, considering not only that $\mathrm{CO}$ can be established and nurtured in the salesperson's mindset in a relatively easier way than EL but also the cross-sectional nature of the study, it is decided that the moderating role of $\mathrm{CO}$ is investigated in the relationship between EL and ASB. 
should be constrained to mental abilities relevant to emotional and cognitive interaction. Consistent with their contention, EI has been defined as "the ability to obtain and apply information on self or others' emotions in order to derive positive results in social situations (Kidwell et al. 2011; p. 78)." In other words, EI does not explain the emotional state per se that an individual experiences through social interaction, but rather focuses on the individual's ability to manage and control emotional experiences. In a similar but broader vein, Mayer et al. (2008) also defined EI as "the ability to assess emotions of self and others, the ability to effectively regulate the emotions of self and others, and the ability to utilize emotions in order to plan one's life and make achievements (p. 78).”

The positive relationship between EI and job performance can easily be found in a number of previous studies in the domains of occupational and social psychologies. An individual who possesses a high level of EI was found to show excellent leadership abilities (Côté, Lopes, Salovey, and Miners 2010) and a high level of achievement by effectively overcoming stress during work through correct perception and control over experienced emotions (Day, Therrien, and Carroll 2005; Slaski and Cartwright 2002, 2003). In addition, individuals of the high EI can effectively cope with negative emotions (e.g., anger, envy) that occur in performing duties by appropriately perceiving, understanding, and controlling various emotions (Tsaousis and Nikolaou 2005).
Especially, service workers and salespeople who have direct encounters with customers may well be able to understand and use negative and positive emotions that occur during the course of interaction with the customer to form a desirable marketing exchange relationship (Kidwell et al. 2011). To enhance organizational performance, service workers and salespeople are expected to not only perceive in which type of emotional states the customers are (McCollKennedy, Patterson, Smith, and Brady 2009) but also let customers experience higher levels of service and satisfaction by managing their emotions and maintaining them positive (Ladhari 2007; Wirtz and Bateson 1999).

On the other hand, service workers and salespeople cannot maintain positive emotions all the time while they perform their tasks, although they understand that expressing desirable emotions is important for providing customers with positive experiences. Hence, they are often put in a situation in which they have to express feelings different from their intrinsic emotions during interaction with customers. This expectation of constant and desirable emotional expressions from the service provider is called 'display rules' which can be defined as the rules of specifying the range, density, duration, and object of emotions displayed within the context of the workplace (Ashforth and Humphrey 1993). In studies of service field, the difference between the intrinsic emotional state and the regulated emotional expressions is called "emotional dissonance 
(Hochschild 1983).' Emotional dissonance has been conceived as the main source of stress that salespersons or service workers can experience while performing their job duties (Grandey 2003). In other words, "the management of feeling to create a publicly observable facial and bodily display (p.7)" was referred to as EL by Hochschild (1983). Though there have been different approaches to EL (e.g., Brotheridge and Lee 2003; Glomb and Tews 2004), the construct can be defined as the labor of adapting one's emotions to conform to the display rules. In the context of salesperson behavior, EL can be understood as the salesperson's behavioral strategy to derive positive achievement by managing the discrepancy between the intrinsic emotional state and the regulated emotional expressions that is experienced during the course of providing selling service (James 1989). Hence, we define EL as 'the salespeople's behavioral trend to control emotions and expressions of self during interaction with customers for achievement of organizational goals in our study context of selling (Grandey 2000). That is, EL is viewed as the salesperson's effort to overcome emotional discrepancy and derive desirable sales behavior rather than the psychological expense that should be paid to maintain desirable emotional states.

The EL strategies that salespersons use can be then categorized into 'surface acting' and 'deep acting' (Ashforth and Humphrey 1993). Surface acting is the behavioral strategy which can be used by salespersons when they pretend that they have positive emotions which are different from the negative emotions they are actually feeling. That is, salespersons regulate their emotional display (e.g., facial expressions, body language, and voice) by using the display rules. In contrast, deep acting is the behavioral strategy which can be used by salespersons as they actually experience the emotions that are in accordance with the display rules. Thus, they make efforts to genuinely feel the emotions that are required by the display rules and actively suppress negative emotions in order to derive desirable emotions from deep inside while confronting customers. By definition, therefore, whereas there might be a large discrepancy between actual feelings and faked emotional expressions in surface acting, there is little difference between inner emotions and expressed feelings in deep acting.

What would be then the relationship between $\mathrm{EI}$ and EL in the selling context? Indeed, there have not been many studies on the relationship between EI and EL in general (Opengart 2005). Further, in the psychology literature, there is little agreement regarding the relationship between $\mathrm{EI}$ and surface acting, while EI has shown a consistent, positive relationship with deep acting (e.g., Brotheridge 2006; Cheung and Tang 2009; Liu et al. 2008). Specifically, except for a few studies that revealed negative relationships between EI and surface acting (e.g., Austin, Dore, and O'Donovan 2008), other studies did 
not find any significant relationships between them (e.g., Cheung and Tang 2009; Johnson and Spector 2007; Lee 2011; Liu et al. 2008; Monaghan 2006; Totterdell and Holman 2003).

Nevertheless, it is posited that, in the context of sales exchanges, the clear relationship between $\mathrm{EI}$ and EL can be found given that salespersons are put in the more goal-oriented situation than people in other situations. By definition, EI refers to the very abilities that are required to perform EL, implying that EI may be directly related to EL (Kidwell et al. 2011; Liu et al. 2008). A salesperson has to perceive what kind of emotions can be accepted and then should regulate his or her emotions to display appropriate expressions of emotion in the context of the sales exchange. EI would then aid salespersons to manage their ELs more effectively in the selling process by abiding by the display rules so that they can enhance customer satisfaction and obtain positive outcomes.

Especially, people with high EI would be more flexible in regulating their emotions so that their feelings are appropriate to the situation (Mayer and Salovey 1997). In general, salespersons may engage more in deep acting due to the situation which pushes them to regulate their emotions effectively. Nevertheless, salespersons with high EI are expected to perform both surface and deep acting because they can perceive and regulate emotions of self and others effectively in correspondence with situational requirements (Chenung and Tang 2009). On the other hand, salespeople with lower EI are expected to inappropriately use EL since their abilities to perceive and regulate emotions are lower. Hence, we propose the following relationships between salespersons' EI and EL. Especially, it needs to be noted that the flexible relationships of $\mathrm{EI}$ with EL, such as positive relationships of $\mathrm{EI}$ with not only deep acting but also surface acting, are firstly and uniquely supposed in the selling context which represents the highly goal-oriented situations in general.

\section{H1-1: Salesperson's EI is positively related to deep acting.
H1-2: Salesperson's EI is positively related to surface acting.

\subsection{Emotional Labor, Adaptive Selling Behavior and Sales Performance}

ASB was defined as "changing the selling behavior of self based on the perceived information related to selling products that is acquired by the salesman during interaction with the customer (Sujan 1986, p. 42)." The salespersons of adaptive selling abilities can change marketing communications with the customer flexibly in the manner conducive to the individual sales situations and/or customer characteristics in order to make the product or service look very attractive. This flexibility enables the salesperson not only to effectively use various types of information which is obtained during contact with the customer but to apply various 
selling behaviors appropriately. Through ASB, the salesperson can form more desirable relationships with customers by applying communication strategies that are most suitable for the situation (e.g., Boorom, Goolsby, and Ramsey 1998; Spiro and Weitz 1990; Sujan, Weitz, and Sujan 1988; Weitz, Sujan, and Sujan 1986).

Further, ASB is based on the theoretical assumption that salespersons can obtain the high-quality information from the customer through interpersonal contacts and regulate their selling behavior, using the acquired information (Franke and Park 2006). Accordingly, previous studies have focused on the effects of cognitive variables such as the salesperson's ability to collect and/ or process information on the change of marketing communication strategies salespeople use (McIntyre, Claxton, Anselmi, and Wheatley 2000; Sujan, Weitz, and Kumar 1994; Weitz, Sujan, and Sujan 1986). Hence, Spiro and Weitz (1990) emphasized that the ability to obtain necessary information through interaction with customers and possession of the knowledge structure to use this information effectively would be the important requirements for salespersons who intend to perform effective and adaptive selling behavior.

On the other hand, the concept of EI implies that salespersons can use not only cognitive information processing but also emotional information processing during the interaction process with the customer (Kidwell et al. 2011). In general, we posit that EI would help salespersons to conduct ASB that reflects the emotional information exchange during the sales situation. The salesperson's EI not only works as mental abilities that are required to obtain emotional information but also forms an emotional knowledge structure that can be used effectively to select the adaptive selling behavior suitable for the situation.

Specifically, EI, as psychological resources, is predicted to affect ASB via EL that operates as behavioral strategies for emotional management. The salesperson plans and regulates emotional expressions as a part of desirable selling behavior based on emotional information gained through EI. During this process, it is highly probable that different levels of dissonance occur between the desirable emotional expressions required to conduct ASB and the actual emotions that the salesperson experiences. Thus, EL with different levels of dissonance is likely to differently affect the salesperson's ASB.

In case of surface acting, a rapport with the customer may be difficult to be formed and the salesperson can hardly react to emotional changes of the customer since the resources of EI are used much to 'fake' desirable emotions superficially (Hennig-Thurau et al. 2006). When salespersons use surface acting as the main behavioral strategy in order to express desirable emotional expressions during interactions with the customer, they are expected to experience a high level of emotional dissonance and concentrate on emotional resources for managing the emotional stress that comes out of the process (Grandey 
2003). Consequently, the salesperson would feel difficulties in securing emotional resources necessary to obtain information on the customer's emotional changes, and thus provides fairly identical services that do not properly incorporate the customer's needs and change of emotional states (King and Emmons 1990).

On the other hand, salespersons who utilize deep acting would make efforts to derive desirable emotions from deep inside their mind during interactions with the customer, and thus their emotional stress may decrease because the gap between the emotions that they express and the emotions that they actually feel diminishes (Grandey 2003). Therefore, they do not need much emotional resources to manage the emotional stress that occurs during the course of duty and the remaining resources can be utilized to understand the customer situations. Consequently, salespersons using deep acting are very likely to make deep rapports with customers. So, they can perform active ASB that appropriately reacts to the customer's emotional change by acquiring the high-quality emotional information from them. Thus, we derive the following hypotheses regarding the relationships between the two behavioral strategies of EL and ASB. It needs to be kept in mind that this research first examines the relationship between EL and ASB in the context of sales exchanges.

H2-1: Salesperson's deep acting is positively related to $A S B$.
H2-2: Salesperson's surface acting is negatively related to $A S B$.

ASB was found to have a significant relationship with sales performance in most previous studies (e.g., Boorom et al. 1998; Spiro and Weitz 1990; Weitz et al. 1986) except for a few studies which found non-significant relationship between the two constructs (e.g. Anglin, Stolman, and Gentry 1990; McMurrian 1996). The inconsistencies in the study findings were attributed to the fact that the studies used different definitions and measures (e.g., selfreported performance vis-à-vis performance measured by indicators; Sujan et al. 1994). To resolve this dispute, Franke and Park (2006) conducted a meta-analysis of the studies related to $\mathrm{ASB}$, reporting that $\mathrm{ASB}$ has positive effects on both self-reported performance and performance assessed in terms of objective indicators based on the cumulative parameters from almost all related studies. Therefore, it is expected that ASB would positively affect both subjective and objective performances. Nevertheless, based on the argument of extant studies that subjective and objective sales outcomes should not be conceived as the identical concept (e.g., Bommer, Johnson, Rich, Podsakoff, and Mackenzie 1995), each type of performance is included in the separate hypotheses.

H3-1: Salesperson's ASB is positively related to subjective sales performance. 
H3-2: Salesperson's ASB is positively related to objective sales performance.

\subsection{Moderating Effects of Customer Orientation}

CO has been much examined along with ASB to constitute effective selling behaviors leading to sales performance (Franke and Park 2006). Accordingly, this research aims to examine the relationship of $\mathrm{EL} \rightarrow \mathrm{ASB}$ along with $\mathrm{CO}$. To conceptualize this relationship, the prior research is reviewed on the relationship between $\mathrm{CO}$ and ASB. Almost all studies found correlational relationships between $\mathrm{CO}$ and ASB. Nevertheless, the causal relationship is not clear (Franke and Park 2006) in that some prior studies found that CO influenced ASB (e.g., Bodkin 1989; Lee and Ji 2013; Spiro and Weitz 1990) and others found vice versa (e.g., Siguaw 1991). Facing this uncertainty, we decided to follow the suggestion of Franke and Park (2006) that distinguishing between customer-oriented attitudes and behaviors and examining the role of empathy may shed additional light on the relationship between $\mathrm{CO}$ and ASB.

First, when the prior research on salesperson's $\mathrm{CO}$ is examined, there exist two streams of research. The first stream considered $\mathrm{CO}$ to be a personal trait that could be developed and acquired through performing job tasks (e.g., Brown, Mowen, Donavan, and Licata 2002; Stock and Hoyer 2005). The other approach regarded $\mathrm{CO}$ as a concept related to organizational culture, influenced by market orientation of the corporation. Integrating these streams, Roman and Iacobuci (2010) emphasized that CO does not exist as simple individual traits or as a part of organizational culture but rather should be perceived as a dynamic concept created by the interaction between the two constructs. They indeed re-conceptualized $\mathrm{CO}$ as a concept that simultaneously reflects individual characteristics and characteristics of the organizational culture, overcoming the inherent limitations of the existent approaches of previous studies. Specifically, corporations with a strong market-orientation form a culture in which the customer's needs are continuously monitored and the efforts should be made to meet them (Day 1994; Sinkula 1994). Though the market-oriented culture may bring about the effect of increasing $\mathrm{CO}$ of each individual employee, there could be variations in the level of each employee's CO because it depends on the extent to which he or she has internalized or perceived the organizational culture. Hence, based on Roman and Iacobuci (2010), this research defines $\mathrm{CO}$ as the salesperson's perception (i.e., attitudes) on how much the organization focuses on the customers' needs and intends to establish a desirable long-term marketing relationship. That is, we revised to use the CO scales of Saxe and Weitz (1982) to reflect attitudinal orientation instead of behaviors. Next, considering that examining the role of empathy may shed additional light on the 
relationship between $\mathrm{CO}$ and $\mathrm{ASB}$, it is decided that EL is examined as the emotionally-driven antecedent of $\mathrm{ASB}$, while $\mathrm{CO}$ as the cognitivelydriven antecedent of ASB. Although this one piece of research cannot perfectly solve the causal relationship between $\mathrm{CO}$ and $\mathrm{ASB}$, it attempted to incorporate the assessment of the antecedent role of EL on ASB along with the moderating effect of $\mathrm{CO}$ on the route of $\mathrm{EL} \rightarrow$ ASB.

In the next is presented our conceptualization regarding the moderating role of the salesperson's $\mathrm{CO}$ in the relationship between EL (deep acting and surface acting) and ASB. First, salespersons with the high level of $\mathrm{CO}$ would not only perceive that the organization as well as themselves value the efforts to identify and satisfy customers' needs but also attempt to express various emotions through deep acting as desirable selling behavior. In other words, salespersons would perform deep acting more actively because they think doing so is consistent with the customer orientation of themselves and their organization, i.e., a synergistic effect of EL (deep acting) and CO on ASB. On the other hand, if salespersons who conduct deep acting are not assured of the customer orientation of themselves as well as the organization, they would attribute their deep-acting behavior, such as building rapport with customers and expressing genuine emotional expressions, to their own efforts. In other words, although they think they are doing their best for deep acting, they are likely to perceive that their ASB may not be fully fulfilled due to the relatively low level of $\mathrm{CO}$. Then, the influence of deep acting on ASB in the low level of CO would be weakened.

Meanwhile, it was previously expected that the salesperson, who uses surface acting as the main behavioral strategy, would feel difficulties in securing emotional resources necessary to obtain information on the customer's emotional changes and thus provide identical services that do not properly incorporate the customer's needs and change of emotional states: i.e., do not perform ASB well (King and Emmons 1990). If this person works in the context of high $\mathrm{CO}$, the person would feel a high level of dissonance in that he or she cannot help but to use monotonous emotional expressions, despite knowing that such a surface acting is not recommended by the selling organization. Hence, this high level of dissonance would interfere with the salesperson's ASB. On the other hand, if salespersons work in the context of low CO, they would feel a certain level of dissonance since they would also perceive restraining their actual emotions and showing monotonous but positive emotional expressions. What is important, though, is that they would feel a relatively lower level of dissonance than salespersons of high $\mathrm{CO}$, suggesting that their ASB would be interfered with less than ASB of salespersons in the context of high CO. That is, the negative effect of surface acting on ASB may be ironically weakened in the case of low CO. In other words, salespeople 
of low CO may perceive not only that their selling jobs are to do surface acting to please customer feelings and emotions regardless of their intrinsic emotions but also that their surface acting may represent ASB efforts.

In sum, our following hypotheses reflect the double-edged aspects of $\mathrm{CO}$ when it is coupled with the salesperson's EL. That is, a high level of $\mathrm{CO}$ would work as a catalyst to activate more ASB for salespersons using deep acting, whereas it rather strengthens the negative relationship between surface acting and ASB.

H4-1: In the higher level of CO, the positive relationship between deep acting and $A S B$ would be stronger.

H4-2: In the higher level of CO, the negative relationship between surface acting and $A S B$ would be stronger.
The conceptualization of our hypotheses is summarized in the research model of Figure 1.

\section{Methods}

\subsection{Sample and Data Collection}

A survey method was used for the study. Five hundred questionnaires were distributed to the sales employees from insurance, security, and other type of financial companies, whose job function is commonly characterized by the high level of interactions with customers. ${ }^{2)}$ From these distributed questionnaires, 409 surveys were collected in person, and 73 responses that included missing values or insincere responses were excluded, leaving 336 questionnaires for

〈Figure 1〉 The Research Model

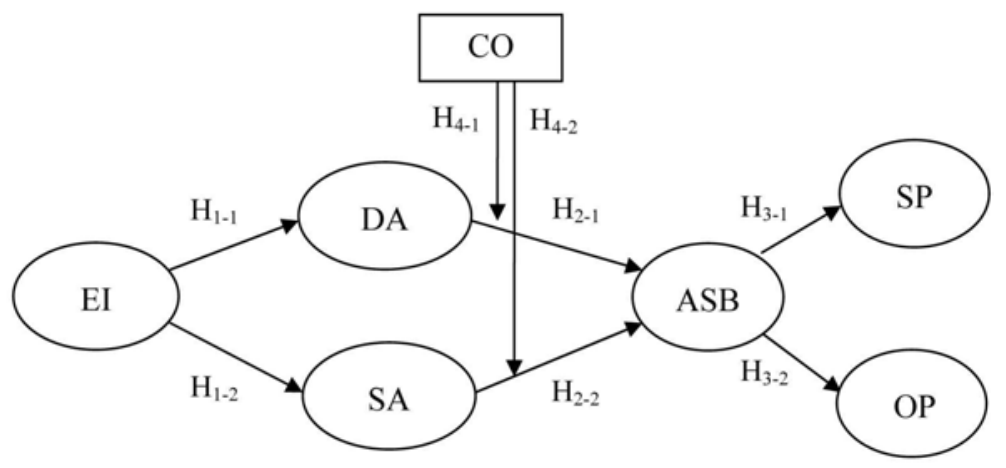

Note. $\mathrm{EI}=$ emotional intelligence, $\mathrm{CO}=$ customer-orientation, $\mathrm{DA}=$ deep acting, $\mathrm{SA}=$ surface acting,

$\mathrm{ASB}=$ adaptive selling behavior, $\mathrm{SP}=$ subjective performance, $\mathrm{OP}=$ objective performance.

2) The majority of respondents were from insurance companies (85.4\%), while some were from security $(9.2 \%)$ and mutual aid $(5.4 \%)$ companies. These companies have communality in terms of selling financial products. 
the data analysis. The demographic characteristics of the sample are presented in Table 1. Male and female respondents took $67 \%$ and $33 \%$, respectively. Thirties $(45.2 \%)$ and forties $(33.0 \%)$ in terms of age, college/university graduates $(68.8 \%)$ in terms of academic background, married (65.8\%) in terms of marital status, 3 4 years (25.9\%) and 5 10 years (24.1\%) in terms of years of tenure, and incentive-based contract (67.6) in terms of employment type were majorities. The characteristics of respondents suggest that they could respond to the questions based on their selling knowledge and experience.

\subsection{Measures}

To test the research hypotheses, the measure items were adapted from the instruments of previous studies that assessed EI, EL, CO, $\mathrm{ASB}$, and sales performance. The measurement items are listed in the Appendix. For the items of EI, the 16 items of Wong and Law's (2002) WLEIS (Wong and Law Emotional Intelligence Scale) were used, which had been validated in various organizational settings. This measurement uses a five-point Likert scale and is composed of four dimensions, i.e., appraisal of self-emotion, appraisal of others' emotion, use of emotion, and regulation of emotion, which are reflective of the construct definition proposed by Kidwell et al. (2011) and Mayer et al. (2008). Next, EL was defined as the degree to which salespersons make efforts to regulate their feelings and expressions in order to express desirable emotions in organizations (Ashforth and Humphrey 1993; James 1989). To measure salespersons' deep acting and surface acting, six items were adapted from the EL scale developed by Brotheridge and Lee (2003). CO was defined as the salesperson's level of understanding customer needs and the

〈Table 1〉 Demographic Characteristics of the Sample

\begin{tabular}{|c|c|c|c|c|c|c|c|}
\hline \multicolumn{2}{|c|}{ Demographics } & \multirow{2}{*}{$\begin{array}{c}\text { Number } \\
225 \\
111\end{array}$} & \multirow{2}{*}{$\begin{array}{c}\text { Percentage } \\
(\%)\end{array}$} & \multicolumn{2}{|c|}{ Demographics } & \multirow{2}{*}{\begin{tabular}{|c|} 
Number \\
221 \\
115
\end{tabular}} & \multirow{2}{*}{$\begin{array}{c}\text { Percentage } \\
(\%)\end{array}$} \\
\hline Gender & $\begin{array}{l}\text { Male } \\
\text { Female }\end{array}$ & & & Marital status & $\begin{array}{c}\text { Married } \\
\text { Single }\end{array}$ & & \\
\hline \multirow[t]{2}{*}{ Age } & $\begin{array}{l}20-29 \\
30-39 \\
40-49\end{array}$ & $\begin{array}{c}39 \\
152 \\
111\end{array}$ & $\begin{array}{l}11.6 \\
45.2 \\
33.0\end{array}$ & $\begin{array}{l}\text { Employment } \\
\text { type }\end{array}$ & $\begin{array}{l}\text { Full-time } \\
\text { Incentive } \\
\text { contract }\end{array}$ & $\begin{array}{l}109 \\
227\end{array}$ & $\begin{array}{l}32.4 \\
67.6\end{array}$ \\
\hline & $\begin{array}{c}50-59 \\
\text { Over } 60 \\
\end{array}$ & $\begin{array}{c}26 \\
8\end{array}$ & $\begin{array}{l}7.7 \\
2.4 \\
\end{array}$ & \multirow{2}{*}{$\begin{array}{l}\text { Years of } \\
\text { tenure }\end{array}$} & $\begin{array}{l}\text { Less than } 1 \\
1-2 \text { years }\end{array}$ & $\begin{array}{l}76 \\
64\end{array}$ & $\begin{array}{l}22.6 \\
19.0\end{array}$ \\
\hline \multirow{2}{*}{$\begin{array}{c}\text { Academic } \\
\text { level }\end{array}$} & \multirow{2}{*}{$\begin{array}{l}\text { Under high school, } \\
\text { High school, } \\
\text { College, } \\
\text { University, } \\
\text { Graduate school }\end{array}$} & \multirow{2}{*}{$\begin{array}{c}3 \\
80 \\
61 \\
170 \\
22\end{array}$} & \multirow{2}{*}{$\begin{array}{c}0.9 \\
23.8 \\
18.2 \\
50.6 \\
6.5\end{array}$} & & $\begin{array}{c}3-4 \text { years } \\
5-10 \text { years } \\
\text { More than } 10\end{array}$ & $\begin{array}{l}87 \\
81 \\
28 \\
\end{array}$ & $\begin{array}{c}25.9 \\
24.1 \\
8.3\end{array}$ \\
\hline & & & & Industry & $\begin{array}{l}\text { Insurance } \\
\text { Security } \\
\text { Mutual aid }\end{array}$ & $\begin{array}{c}287 \\
31 \\
18 \\
\end{array}$ & $\begin{array}{c}85.4 \\
9.2 \\
5.4\end{array}$ \\
\hline
\end{tabular}


degree to which they try to satisfy them (Roman and Iacobuci 2010). Seven items were adapted from the SOCO (selling-orientation and customer-orientation scale) developed by Saxe and Weitz (1982) and revised to represent customer-oriented attitudes (Franke and Park 2006).

ASB was defined as the extent to which a salesperson develops knowledge necessary for each sales situation and applies it at work (Franke and Park 2006). The items were adapted from Marks, Vorhies, and Badovick, (1996) and Park and Holloway's (2003) measurements, which are based on the ADAPTS (Spiro and Weitz 1990). For the measurement of the salesperson's performance, items from Park and Holloway (2003), which were developed based on Sujan, Weitz and Kumar (1994), were modified into self-report-based questions. In addition, given that the use of objective performance is preferred to subjective performance when the salesperson's performance is appraised, the number of monthly completed transactions and sales results were used to assess objective performance of individuals. Further, log transformation of objective performance was used as the distribution was extremely skewed to the right, violating the assumption of normal distribution.

\subsection{Common Method Biases}

The Harman one-factor test was performed to assess the potential for common method bias in the data (Podsakoff and Organ 1986). After the careful item purification, an un-rotated factor analysis of the dependent and independent variables results in a solution that accounts for $64.61 \%$ of the total variance, and the first factor accounts for $28.05 \%$ of the variance indicating that common method biases are not a likely contaminant of our results.

Moreover, common method bias usually arises from having a common rater or from the characteristics of the items themselves (Podsakoff, MacKenzie, Lee and Podsakoff 2003). To prevent this problem, the questionnaire was very carefully designed from the beginning. Before collecting data, we made efforts to ensure that the measureitems, developed based on prior literature, were examined by practitioners in the field, decreasing the source of non-sampling errors as much as possible. The items that were not well articulated were revised, and grammatical errors were corrected. Furthermore, we allowed the respondents' answers to be anonymous and assured them that there were no right or wrong answers and they answered the questions as honest as possible. This procedure should reduce the respondents' evaluation apprehension and the tendency of being socially desirable which is also an arguable source of common method effects produced by a common rater (Podsakoff et al. 2003). 


\section{Analyses \& Results}

\subsection{Descriptive Statistics and Correlations}

Descriptive statistics and correlations between the variables included in the research model are presented in Table 2. The correlations among the variables were significant at the level of a $=.01$ except for the correlation between OEA and $\mathrm{OP}(\mathrm{r}=-.04)$ and the correlation between SEA and OP $(r=.08)$, the correlation between $\mathrm{SA}$ and $\mathrm{OP}(\mathrm{r}=.00)$ and the correlation between ASB and OP $(r=.09)$. The correlation between ASB and SP was the highest $(r=.68)$, while the correlation between ROE and OP was the lowest $(r=-.12)$. Moreover, Cronbach's alphas in the parentheses indicate that the measurements used in this study have in general high level of reliability.

\subsection{Assessment of the Measurement Model}

Before examining the fitness of the structural model, confirmatory factor analysis (CFA) was conducted first to assess the measurement model, following the two-step approach for structural equation modeling (Jöreskog and Sörbom 1996). AMOS 17.0 was used to analyze the data, and it was found that the standardized factor loadings of the indicators were in an acceptable range of 0.57 and 0.94 . In addition, the model fit estimates indicated that the measurement

〈Table 2〉 Descriptive Statistics and Correlations

\begin{tabular}{|c|c|c|c|c|c|c|c|c|c|c|}
\hline Variables $^{\mathrm{a}}$ & 1 & 2 & 3 & 4 & 5 & 6 & 7. & 8 & 9 & 10 \\
\hline 1. OEA & $(.810)$ & & & & & & & & & \\
\hline 2. SEA & $.686^{* *}$ & $(.853)$ & & & & & & & & \\
\hline 3. UOE & $.581^{* *}$ & $.656^{* *}$ & $(.829)$ & & & & & & & \\
\hline 4. ROE & $.550^{* *}$ & $.643^{* *}$ & $.566^{* *}$ & $(.862)$ & & & & & & \\
\hline 5. DA & $.549^{* *}$ & $.585^{* *}$ & $.552^{* *}$ & $.419^{* *}$ & $(.790)$ & & & & & \\
\hline 6. SA & $.287^{* *}$ & $.242^{* *}$ & $.233^{* *}$ & $.271^{* *}$ & $.332^{* *}$ & $(.697)$ & & & & \\
\hline 7. CO & $.577^{* *}$ & $.593^{* *}$ & $.584^{* *}$ & $.432^{* *}$ & $.669^{* *}$ & $.249^{* *}$ & $(.891)$ & & & \\
\hline 8. ASB & $.602^{* *}$ & $.576^{* *}$ & $.610^{* *}$ & $.431^{* *}$ & $.597^{* *}$ & $.269^{* *}$ & $.684^{* *}$ & $(.869)$ & & \\
\hline 9. SP & $.468^{* *}$ & $.443^{* *}$ & $.579^{* *}$ & $.384^{* *}$ & $.452^{* *}$ & $.234^{* *}$ & $.538^{* *}$ & $.683^{* *}$ & $(.858)$ & \\
\hline 10. OP & -.043 & .079 & .039 & $-.123^{*}$ & $.145^{*}$ & .000 & .001 & .085 & .028 & $(.725)$ \\
\hline MEAN & 3.80 & 3.89 & 3.78 & 3.64 & 3.81 & 3.35 & 4.07 & 3.63 & 3.62 & 0.33 \\
\hline S.D & .688 & .705 & .742 & .780 & .700 & .778 & .645 & .675 & .735 & .312 \\
\hline
\end{tabular}

Note: $\mathrm{N}=336,{ }^{*} \mathrm{p}<.01,{ }^{*} \mathrm{p}<.05$, the numbers in parentheses are Cronbach Alpha coefficients.

a) $\mathrm{OEA}=$ other's emotion appraisal, $\mathrm{SEA}=$ self- emotional appraisal, $\mathrm{UOE}=$ use of emotion, $\mathrm{ROE}=$ regulation of emotion, DA = deep acting, $\mathrm{SA}=$ surface acting, $\mathrm{CO}=$ customer orientation, $\mathrm{ASB}=$ adaptive selling behavior, $\mathrm{SP}$ $=$ subjective performance, $\mathrm{OP}=$ objective performance (log transformed). 
model appropriately fit the data $\left(\chi^{2}=1381.14\right.$, $\mathrm{df}=575 ; \quad \mathrm{RMR}=0.046 ; \quad \mathrm{GFI}=0.814 ; \mathrm{TLI}=$ 0.969; $\mathrm{CFI}=0.972$; RMSEA $=0.065$ ).

As presented in Table 3, the average variance extracted (AVE) for each variable was computed in order to review the discriminant validity of the variables. The range of AVEs was from 0.662 to 0.857 , which satisfied the criteria of over 0.50 (Fornell and Larcker 1981). Thus, it can be said that all the variables have discriminant validity. As for composite reliability, all the variables, except for surface acting (0.565), satisfied the acceptable criteria (Hair, Anderson, Tatham, and Black 2006).

\subsection{Assessment of the Structural Model}

The research hypotheses were tested with significance tests and a bootstrapping with 5000 resampling, and the results are presented in Table 4.

〈Table 3〉 The Results of Confirmatory Factor Analysis

\begin{tabular}{|c|c|c|c|c|c|c|c|}
\hline \multicolumn{3}{|c|}{ Variables } & Items & $\mathrm{CCR}$ & $\begin{array}{c}\text { Standard } \\
\text { factor loading }\end{array}$ & C.R. & AVE \\
\hline \multirow{4}{*}{ EI } & \multicolumn{2}{|c|}{ ROE } & 4 & \multirow{4}{*}{.838} & .76 & 12.029 & \multirow{4}{*}{.857} \\
\hline & \multirow{2}{*}{\multicolumn{2}{|c|}{$\begin{array}{l}\text { OEA } \\
\text { UOE }\end{array}$}} & 4 & & .87 & 12.584 & \\
\hline & & & 4 & & .86 & 11.413 & \\
\hline & \multicolumn{2}{|c|}{ SEA } & 4 & & .94 & 14.119 & \\
\hline \multirow{2}{*}{ EL } & DA & $\begin{array}{l}\text { Q2_01 } \\
\text { Q2_04 } \\
\text { Q2_06 }\end{array}$ & 3 & .690 & $\begin{array}{l}.74 \\
.78 \\
.72\end{array}$ & $\begin{array}{c}- \\
12.857 \\
12.050\end{array}$ & .748 \\
\hline & SA & $\begin{array}{l}\text { Q2_02 } \\
\text { Q2_03 } \\
\text { Q2_05 }\end{array}$ & 3 & .565 & $\begin{array}{l}.61 \\
.73 \\
.64\end{array}$ & $\begin{array}{c}- \\
7.956 \\
7.884\end{array}$ & .662 \\
\hline ASB & \multicolumn{2}{|c|}{$\begin{array}{l}\text { Q4_01 } \\
\text { Q4_02 } \\
\text { Q4_03 } \\
\text { Q4_04 } \\
\text { Q4_05 } \\
\text { Q4_06 } \\
\text { Q4_07 }\end{array}$} & 7 & .625 & $\begin{array}{l}.70 \\
.64 \\
.57 \\
.79 \\
.80 \\
.66 \\
.74\end{array}$ & $\begin{array}{r}- \\
10.956 \\
9.799 \\
13.389 \\
13.508 \\
11.245 \\
12.604\end{array}$ & .701 \\
\hline $\mathrm{SP}$ & \multicolumn{2}{|c|}{$\begin{array}{l}\text { Q5_01 } \\
\text { Q5_02 } \\
\text { Q5_03 } \\
\text { Q5_04 } \\
\text { Q5_05 }\end{array}$} & 5 & .678 & $\begin{array}{l}.72 \\
.71 \\
.76 \\
.76 \\
.74\end{array}$ & $\begin{array}{c}- \\
12.162 \\
13.061 \\
13.063 \\
12.771\end{array}$ & .740 \\
\hline $\mathrm{OP}$ & \multicolumn{2}{|c|}{$\begin{array}{l}\text { Q5_06 } \\
\text { Q5_07 }\end{array}$} & 2 & .824 & $\begin{array}{l}1.01 \\
.67\end{array}$ & $\begin{array}{c}- \\
3.429\end{array}$ & .842 \\
\hline
\end{tabular}

Note: $\mathrm{N}=336$ 
Estimates of the model fit indices for the structural model $\left(\chi^{2}=1432.61, \mathrm{df}=584 ; \mathrm{RMR}\right.$ $=0.051 ; \mathrm{GFI}=0.808 ; \mathrm{TLI}=0.968 ; \mathrm{CFI}=0.970$; RMSEA $=0.066)$ generally satisfied the criteria provided by Hair et al. (2006). The results of testing the hypotheses are presented in the following.

First, the salesperson's EI showed a significant, positive relationship with deep acting and thus, hypothesis 1-1 was supported (path coefficient $=.83, \mathrm{t}=12.27, \mathrm{p}<.01$, Bootstrap $\mathrm{CI}=.75 \sim$ .90). Since the salesperson's EI also had a significant, positive relationship with surface acting, hypothesis 1-2 was also supported (path coefficient $=.39, \mathrm{t}=5.24, \mathrm{p}<.01$, Bootstrap $\mathrm{CI}=.21 \sim .57)$.

Second, hypothesis 2-1 was supported since the salesperson's deep acting showed a positive relationship with ASB (path coefficient $=.78$, $t=9.87, p<.01$, Bootstrap $\mathrm{CI}=.66 \sim .87)$. Different from our proposition, however, hypothesis 2-2 was not supported because the relationship between the salesperson's surface acting and
ASB was not significant (path coefficient= $.06, \mathrm{t}=1.12, \mathrm{p}>.05$; Bootstrap $\mathrm{CI}=-.05 \sim$ .14). We probed the main reason for why the hypothesis 2-2 was not supported. It appeared at a glance that the relationship of SA with ASB was weaker than that of DA with ASB on the basis of the correlations (.269 vs. .597 in Table 2) as well as the means of ASB for SA and DA (3.71 vs. 4.08). However, we found that salespersons who did SA perceived themselves to normally do ASB if their EI levels were high as compared to low (Means of $\mathrm{ASB}=$ 3.97 (for high SA \& high EI) > 3.41 (for high $\mathrm{SA} \&$ low EI); $\mathrm{p}<.01$ ). Indeed, these persons' level of ASB was not different from that of deep-acting salespersons $(3.97=4.18 ; \mathrm{p}>.05)$. In other words, when salespersons of high EI used SA, they did not appear to experience a high level of emotional dissonance and stress, which would be different from the rationale used for deriving the hypothesis 2-2. As a matter of fact, it is acknowledged that when we drew the hypothesis 2-2, we did not thoroughly

〈Table 4〉 Estimates of Path Coefficients in the Structural Model

\begin{tabular}{|c|c|c|c|c|c|c|c|}
\hline \multirow{2}{*}{ Hypothesis } & Path & \multirow{2}{*}{$\begin{array}{c}\text { Predicted } \\
\text { Direction of } \\
\text { Effect }\end{array}$} & \multirow{2}{*}{$\begin{array}{c}\text { Standardized } \\
\text { Coefficient }\end{array}$} & T-values & \multicolumn{2}{|c|}{ Bootstrap CI } & \multirow{2}{*}{ Result } \\
\cline { 6 - 8 } & & & & Lower & Upper & \\
\hline H 1-1 & EI $\rightarrow$ DA & + & .83 & $12.273^{* *}$ & .75 & .90 & Supported \\
\hline H 1-2 & EI $\rightarrow$ SA & + & .39 & $5.244^{* *}$ & .21 & .57 & Supported \\
\hline H 2-1 & DA $\rightarrow$ ASB & + & .78 & $9.873^{* *}$ & .66 & .87 & Supported \\
\hline H 2-2 & SA $\rightarrow$ ASB & - & .06 & 1.115 & -.05 & .14 & Not supported \\
\hline H 3-1 & ASB $\rightarrow$ SP & + & .77 & $10.218^{* *}$ & .62 & .88 & Supported \\
\hline H 3-2 & ASB $\rightarrow$ OP & + & .13 & $1.835^{* *}$ & .02 & .23 & Supported \\
\hline
\end{tabular}


consider the flexible relationship of EI with EL, such as positive relationship of EI with surface acting. That is, salespersons of high EI are expected to perform SA because they can perceive and regulate emotions of self and others effectively if the situation requires (Chenung and Tang 2009).

Third, ASB was found to have a positive relationship with subjective performance and thus, hypothesis 3-1 was supported (path coefficient $=.77, \mathrm{t}=10.22, \mathrm{p}<.01$; Bootstrap $\mathrm{CI}=.62 \sim$ .88). In addition, the relationship between ASB and objective performance was significantly positive, so hypothesis 2-4 was supported (path coefficient $=.13, \mathrm{t}=1.84, \mathrm{p}<.01 ;$ Bootstrap $\mathrm{CI}=.02 \sim .23)$.

In addition, Table 5 further presents the test results of indirect effects from the bootstrapping procedure (Preacher and Hayes 2008).' The roles of multiple mediators were found to be significant except for the case of SA, consistent with the result that the relationship of $\mathrm{SA} \rightarrow$
ASB was not supported. Further, as discussed in the probing regarding hypothesis $2-2$, the path of $\mathrm{SA} \rightarrow \mathrm{ASB}$ was not significant due to the role of EI, which suggested the strong indirect effect of $\mathrm{EI} \rightarrow \mathrm{ASB}$.

Lastly, in order to test the moderating effect of $\mathrm{CO}$ on the relationship between $\mathrm{EL}$ and $\mathrm{ASB}$, the participants were divided into the high and the low level groups of $\mathrm{CO}$ on the basis of the median score $($ median $=4.14)$. Then, the fit of the model that constrained the path to be identical between the groups was compared with that of the unconstrained model by calculating the difference of model $\chi^{2}$. As can be seen in Table 6 , when the coefficient of the 'deep acting $\rightarrow$ ASB' path was fixed to be identical between the two groups, the fit of the constrained model got significantly worse, compared with the unconstrained model $\left(\triangle \chi^{2}(1)=18.432\right.$, $\mathrm{p}<.01)$. In addition, when the coefficient of the 'surface acting $\rightarrow$ ASB' path was fixed to be identical among the high and low customer

〈Table 5〉 Bootstrapping Tests for Indirect Effects

\begin{tabular}{|c|c|c|c|c|}
\hline & Indirect Effect & \multicolumn{2}{|c|}{ Bootstrap CI } & Test Results \\
\hline $\mathrm{EI} \rightarrow \mathrm{ASB}$ & .67 & .56 & .78 & Significant \\
\hline $\mathrm{EI} \rightarrow \mathrm{SP}$ & .44 & .34 & .60 & Significant \\
\hline $\mathrm{EI} \rightarrow \mathrm{OP}$ & .09 & .01 & .17 & Significant \\
\hline $\mathrm{DA} \rightarrow \mathrm{SP}$ & .60 & .46 & .72 & Significant \\
\hline $\mathrm{DA} \rightarrow \mathrm{OP}$ & .10 & .01 & .19 & Significant \\
\hline $\mathrm{SA} \rightarrow \mathrm{SP}$ & .05 & -.03 & .15 & Not Significant \\
\hline $\mathrm{SA} \rightarrow \mathrm{OP}$ & .01 & -.02 & .05 & Not Significant \\
\hline
\end{tabular}

3) We thank for the reviewer's suggestion of this analysis of bootstrapping procedure. 
orientation groups, the fit of the constrained model got significantly worse than that of the unconstrained model $\left(\triangle \chi^{2}(1)=27.803, p<.01\right)$. From these results, we can infer that $\mathrm{CO}$ moderates the relationship of deep acting $\rightarrow$ ASB as well as the relationship of surface acting $\rightarrow$ ASB.

To analyze the direction of the moderating effect of $\mathrm{CO}$ on the relationship of deep acting $\rightarrow$ ASB, the path coefficients were compared between the high CO group and low CO group. The estimated standardized coefficient of the 'deep acting $\rightarrow$ ASB' path was .82 ( $\mathrm{t}$-value $=$ 7.22; $\mathrm{p}<.01)$ for the high $\mathrm{CO}$ group and .51 ( $t$-value $=3.74 ; \mathrm{p}<.01)$ for the low $\mathrm{CO}$ group. Thus, hypothesis $4-1$, which predicted that the positive relationship between deep acting and ASB would get stronger in the higher level of $\mathrm{CO}$, was supported.

On the other hand, the estimated standardized path coefficient of the 'surface acting $\rightarrow$ ASB' path was $-.04(t-v a l u e=-.63 ; p>.05)$ for the high $\mathrm{CO}$ group and $.40(\mathrm{t}-$ value $=3.67 \mathrm{p}<$ .01) for the low $\mathrm{CO}$ group. Even though $\mathrm{CO}$ played the moderating role in the effect of $\mathrm{SA}$ on ASB, the resulting direction of effect was different from the expectation of hypothesis
4-2 that the negative relationship of SA $\rightarrow$ ASB would be found for the low CO group along with the more negative relationship of $\mathrm{SA} \rightarrow \mathrm{ASB}$ for the high $\mathrm{CO}$ group. Instead, the path of SA $\rightarrow$ ASB was found to be nonsignificant for the high $\mathrm{CO}$ group and the path was found to be positive instead of negative for the low CO group. Thus, hypothesis 4-2 was not supported. ${ }^{4)}$ The major reason for why the hypothesis 4-2 was not supported would be attributed to the result that SA was not negatively related to ASB, i.e., the hypothesis 2-2 was not supported due to the versatile role played by EI. Nevertheless, we interpreted the direction of effects in relation to the reasoning used in the derivation of hypothesis 4-2. If the salesperson who uses SA works in the context of high $\mathrm{CO}$, the person may feel a high level of dissonance which would interfere with his or her ASB (Means of $\mathrm{ASB}=3.44$ for the high $\mathrm{CO}$ context $<3.98$ for the low $\mathrm{CO}$ context; $\mathrm{p}<$ .01 ). On the other hand, salespeople of low $\mathrm{CO}$, feeling a relatively lower level of dissonance, may perceive not only that their selling jobs would be to do SA to please customer feelings and emotions but also that their SA may

4) One of the reviewers recommended spotlight analysis as a complementary tool which would help readers understand the directional pattern of the results of H4-1 and H4-2. We strongly agree with the reviewer's concern regarding the limitations of using the dichotomization procedure. Although using product terms of continuous variables and spotlight analysis is a powerful method for displaying insightful graphical patterns of interactions in regression analysis, such an approach may generate serious problems in maximum likelihood estimation in structural equation modeling because the products of indicator variables may produce non-linear and correlated error terms (Ping 1995). Further, since our theoretical hypotheses proposed the changes in the strength of coefficients, we maintained to use the multi-group analysis, recommended by Ping (1995). Nevertheless, we highly appreciate the reviewer's concern and comments. 
〈Table 6〉 Verification of the Moderating Effect of $\mathrm{CO}$

\begin{tabular}{|c|c|c|c|c|}
\hline \multirow{2}{*}{ Path } & \multicolumn{2}{|c|}{$\mathrm{DA} \rightarrow \mathrm{ASB}$} & \multicolumn{2}{c|}{ SA $\rightarrow$ ASB } \\
\cline { 2 - 5 } Model & $\chi^{2}$ & $\Delta \chi^{2}$ & $\chi^{2}$ & $\triangle \chi^{2}$ \\
\hline $\begin{array}{c}\text { Unconstrained model } \\
(d f=1242)\end{array}$ & 2513.154 & - & 2513.154 & $27.803^{* *}$ \\
\hline $\begin{array}{c}\text { Constrained model } \\
(d f=1241)\end{array}$ & 2494.822 & $18.332^{* *}$ & 2485.351 & \\
\hline
\end{tabular}

represent $\mathrm{ASB}$ efforts (Means of $\mathrm{ASB}=3.44$ for the high $\mathrm{CO}$ context $<3.98$ for the low $\mathrm{CO}$ context; $\mathrm{p}<.01$ ). Hence, although the hypothesis 4-2 was not supported in terms of the directions of effect, the reasoning behind the hypothesis was roughly consistent with the result.

\section{Discussion}

\subsection{Summary of the Findings}

Our research examined the effects of salespersons' $\mathrm{EI}$ and EL on ASB and sales performance along with the moderating role of $\mathrm{CO}$ in the route of EL to ASB. The findings of the research are summarized as follows. First, it was found that salespersons with a high level of EI used both deep acting (regulating the emotions themselves) and surface acting (controlling only emotional expressions) in a versatile way, when implementing EL. Since deep acting is the process of controlling one's emotions spontaneously, intentional efforts are needed (Hochschild 1983). As for surface acting, however, salespersons control only their emotional expressions and experience. Accordingly, the salesperson of high EI can regulate his or her emotional resources, suggesting that he or she uses deep acting as well as surface acting as the need arises. As a matter of fact, the results of debriefing interviews with about ten 'self-competent' salespersons indicated that they were able to prioritize their selling efforts and conversations (regulate their emotional resources in our terms) after discerning the importance of potential customers, implying the salesperson's versatility of using deep acting and surface acting. Moreover, this finding may play the role of explaining the inconsistent results of previous studies on the relationship between EI and EL by showing simultaneously positive relationships of EI to deep and surface acting, especially in the clear goal-oriented situation.

Second, the more the salesperson performed deep acting, the more he or she showed to do ASB. This finding is generally consistent with previous research which showed that deep acting was positively related to the maintenance of long-term relationships with the customer (Brotheridge and Grandey 2002). It is, then, 
important for salespersons to use deep acting more frequently in the EL process in order to enhance the quality of interacting with customers through ASB. The debriefing interviews showed that salespersons tried to genuinely experience the emotions that they showed in order to maintain touch bases with customers since the highly related customers could really discern real emotions from fake ones.

On the other hand, the salesperson's surface acting did not have a significant relationship with ASB. This specific finding is actually different than our prediction that surface acting is negatively related to ASB. As mentioned in the section of results, the main reason for why this hypothesis was not supported may be that salespersons who did SA perceived themselves to normally do ASB if their EI levels were high. Considering the flexible relationship of $\mathrm{EI}$ with EL, the simple negative relationship of SA with ASB cannot be expected, while the relationship may be complex and different depending upon EI and/or CO.

Next, CO was found to moderate the relationship between the salesperson's EL and ASB. Specifically, as predicted, it was found that in the higher level of $\mathrm{CO}$, the positive relationship between deep acting and ASB was stronger. That is, the context of high $\mathrm{CO}$ culture and individual salesperson's deep acting may synergistically make the selling efforts adaptive to customer preferences.

On the other hand, like a complex relationship between SA and ASB, the moderating effect of $\mathrm{CO}$ in the relationship between the salesperson's surface acting and ASB was found to be complex and different from the expected direction of effects. Specifically, we expected that the negative relationship of SA with ASB would be found for the low CO group along with the more negative relationship of SA with ASB for the high $\mathrm{CO}$ group, while we found that the path of $\mathrm{SA} \rightarrow \mathrm{ASB}$ was positive, instead of negative, for the low $\mathrm{CO}$ group along with non-significant path of $\mathrm{SA} \rightarrow \mathrm{ASB}$ for the high $\mathrm{CO}$ group. Since SA was not negatively related to ASB due to the flexible role played by EI, we may not find the expected direction of effects. When we probed to interpret the results on the direction of effects, the salesperson who uses SA works in the context of high $\mathrm{CO}$ would feel interfered with his or her ASB, while salespeople of low CO may perceive not only that their selling jobs would be to do SA to please customer feelings and emotions but also that their SA may represent $\mathrm{ASB}$ efforts (Means of $\mathrm{ASB}=3.44$ for the high $\mathrm{CO}$ context $<3.98$ for the low $\mathrm{CO}$ context; $\mathrm{p}<.01)$. The debriefing interviews also supported this probing for salespeople of high CO who do SA: “... if I conceal my true emotions and show those demanded by organization and situation, it is very difficult to customize my selling efforts, accommodating consumers' needs and/or wants."

Lastly, consistent with previous studies which found significant relationships between ASB 
and salesperson's performance, we found such a relationship. It is meaningful that we found significant relationships in terms of both subjective and objective performances.

\subsection{Conceptual and Managerial Implications}

The foremost conceptual contribution is that this research examined, first in the sales literature, how EI and EL influence effective selling behavior and salesperson's performance. Specifically, conceptualizing and empirically verifying the antecedent roles of important emotional constructs such as EI and EL in salesperson's effective selling behavior (ASB) and sales performance is a major theoretical contribution in the sales literature.

In addition, this research shows the flexible role of EI such that EI can be linked to not only DA but also SA in correspondence with situational requirements in a clear goal-oriented setting such as selling. It needs to be remembered that in the psychology literature, EI has consistently shown a positive relationship with DA, while there has been little agreement as to the relationship between EI and SA (e.g., Brotherridge 2006). Hence, the proposition and finding that EI would be related in a versatile way to EL (deep acting and surface acting) implies the need to further refine the conceptual relationship between $\mathrm{EI}$ and EL in the related literatures such as educational, occupational, social psychology.
Moreover, although this research finds the versatile role of EI, especially the relationship between EI and SA, it also suggests that the relationship between $\mathrm{SA}$ and $\mathrm{ASB}$ would be quite complex due to this flexible role of $\mathrm{EI}$, which needs further research. From a different angle of effective selling behavior literature, this research attempted to shed additional light on the relationship between $\mathrm{CO}$ and ASB by examining the role of empathy such as emotional regulation processes (EI and EL). Although the synergistic effects of DA and $\mathrm{CO}$ on ASB were found, the relationships among SA, CO, and ASB were still unanswered. Hence, the need for more fine-tuned conceptualization efforts is warranted as to the relationships among SA, $\mathrm{CO}$, and $\mathrm{ASB}$, especially focusing on examining the role of emotional dissonance felt by salespersons in the encounter with customers.

Managerially, this research provides a deeper understanding on the nature of tasks performed by salespersons in service industries and a few guidelines for managing the sales force. First, sales organizations had better consciously assess EI capacity in the selection and nurturing processes of salespeople, given that EI can flexibly drive EL and the resulting effective selling behavior and performance.

As a matter of fact, sales organizations have focused mainly on incentives, salary, and welfare of employees to improve their performance. However, the findings of this study imply that sales managers' understanding the emotional aspect 
of the sales and service process is no less important. The concept of EL could provide a framework to understand the salespersons' emotional experiences in depth. Especially, sales organizations may well think over how to develop deep acting capabilities of their sales representatives, given the facilitating effect of DA on ASB and sales performance. In this direction, the training on deep acting strategies would be an essential task for improving performance of salespersons. This kind of training had better incorporate the perspectives and stories of customers such that many customers can actually discern whether salespersons are doing either surface acting or deep acting.

In addition, a training process had better include acquisition of strategies to control negative emotions (emotional dissonance and stress). An example of the emotion-controlling strategy would be to recall a situation that evokes specific emotions and focus on the positive side of the encountered situation to relieve negative emotions (Grandey 2003). The need gets more imperative for front-line employees in services or sales encounters to be equipped with the emotioncontrolling strategy when the recent accident of a customer riot in the air plane of KAL is reminded of (Ha 2013).

Finally, based on the synergistic effects of deep acting and $\mathrm{CO}$ culture, how to build and sustain CO context is always an ever-important task in sales organizations. While the prior selling literature has emphasized the process and structure of highly customer-oriented sales organization, our research not only corroborates the important aspects of customer-oriented sales organization, but also adds the important dimension of competent sales representatives who can resonate with customers by deep acting for sales excellence.

\subsection{Limitations and Future Research Directions}

Despite the interesting findings, this research has of course some limitations. First, the data was collected from salespersons working in limited industries. Since most of the participants in the sample were salespersons of insurance companies, generalizing the results of this research to salespersons working in other industries may not be appropriate. Because there is a wide range of fields that require EI and EL, data from more diverse industries should be collected in future studies. Further, differences in distinct types of industries need to be conceptualized and empirically examined.

Second, it would be a very interesting and practical future study to examine how the effects of the emotional factors (EI and EL) and the cognitive factor (CO) on ASB and sales performances would differ depending upon the salesperson's individual characteristics such as gender and/or experience which have been found to be important antecedents of ASB in the sales literature (Frank and Park 2006). 
Third, the relative effects of more concrete strategies which can be used by salespersons to conduct deep acting on effective selling behavior and sales performance had better be examined. Although it was verified in this research that the salesperson's use of deep acting positively affected sales outcomes through ASB, the relative effects of different strategies to facilitate deep acting had better be articulated in further studies.

Fourth, future research is needed to precisely assess the reasons why the hypotheses 2-2 and 4-2 were not supported. Specifically, the relationships among $\mathrm{SA}, \mathrm{ASB}$, and $\mathrm{CO}$ need to be deep-dived along with the versatile association of EI with SA. In pursuing this research, precise process aspects such as level of emotional dissonance and/or stress could be investigated to understand the mechanism by which EI could be linked to SA and ASB along with $\mathrm{CO}$.

Fifth, like many other studies, this study is exposed to the limitation which accrues from the use of the self-reporting method in the data collecting process. For instance, it is probable that front-line salespersons may have judged themselves as more customer-oriented, considering the job-related norms and/or the image of their company. Thus, in future research, this methodological limitation should be overcome by using various methods, such as letting the leader or the colleagues measure the members' selling behavior and sales performance. Moreover, the dyadic analysis method in which data is also collected from customers of the salesperson had better be used in order to appraise whether the salesperson actually shows ASB. This dyadic approach can clearly eliminate the plausible common method bias in the data.

Lastly, this research adapted existent tools in the field of educational, occupational, social psychology to measure EI and EL. Nevertheless, development of a new measurement and/or method would be needed to assess variables so as to more precisely incorporate the characteristics of sales situations in future studies. This methodologyrelated concern can promote studies on the emotional phenomenon in the specific context of the sales encounter.

〈Received October 4. 2013〉

〈Revised January 24. 2014〉

〈Accepted January 28. 2014〉

\section{References}

Anglin, K. A., Stolman, J. J., and Gentry, J. W. (1990), "The Congruence of Manager Perception of Salesperson Performance and Knowledge-Based Measures of Adaptive Selling," Journal of Personal Selling \& Sales Management, 10 (4), 81-90.

Ashkanasy, N. M. and Daus, C. S. (2005), "Rumors of the Death of Emotional Intelligence in Organizational Behavior Are Vastly Exaggerated," Journal of Organizational Behavior, 26 (4), 441-452. 
Ashforth, B. E. and Humphrey, R. H. (1993), "Emotional Labor in Service Roles: The Influence of Identity," Academy of $\mathrm{Ma}^{-}$ nagement Review, 18 (1), 88-115.

Austin, E. J., Dore, T. C. P., and O'Donovan, K. M. (2008), "Associations of Personality and Emotional Intelligence with Display Rule Perceptions and Emotional Labor," Personality and Individual Differences, 44 (3), 679-688.

Bagozzi, R. P. (1997), “Goal-directed Behaviors in Marketing: The Role of Emotion, Volition, and Motivation," Psychology \& Marketing, 14 (4), 309-313.

Bodkin, C. D. (1989), “The Adaptive Behavior Construct and Its Effect on Salesperson Performance," unpublished doctoral dissertation, Department of Marketing, Virginia Tech University.

Bommer, W. H., Johnson, J. L., Rich, G. A., Podsakoff, P. M., and Mackenzie, S. B. (1995), "On the Interchangeability of Objective and Subjective Measures of Employee Performance - a Meta-Analysis," Personnel Psychology, 48 (3), 587-605.

Boorom, M. L., Goolsby, J. R., and Ramsey, R. P. (1998), "Relational Communication Traits and Their Effect on Adaptiveness and Sales Performance," Journal of the Academy of Marketing Science, 25 (1), 16-30.

Brotheridge, C. M. and Grandey, A. A. (2002), "Emotional Labor and Burnout: Comparing Two Perspectives of People Work," Journal of Vocational Behavior, 60 (1), 17-39. and Lee, R. T. (2002), "Testing a Conservation of Resources Model of the Dynamics of Emotional Labor," Journal of Occupational Health Psychology, 7 (1), 57-67. and Lee, R. T. (2003), "Development and Validation of the Emotional Labor Scale," Journal of Occupational and Organizational Psychology, 76 (3), 365-379. (2006), "The Role of Emotional Intelligence and Other Individual Difference Variables in Predicting Emotional Labor Relative to Situational Demands," Pscicothema, 18, 139-144.

Brown, T. J., Mowen, J. C., Donavan, D. T., and Licata, J. W. (2002), "The Customer Orientation of Service Workers: Personality Trait Effects on Self- and Supervisor Performance Ratings," Journal of Marketing Research, 39 (1), 110-119.

Cheung, F. Y. and Tang, C. S. (2009), "The Influence of Emotional Intelligence and Affectivity on Emotional Labor Strategies at Work," Journal of Individual Differences, 30 (2), 75-86.

Côté, S., Lopes, P. N., Salovey, P., and Miners, C. T. H. (2010), "Emotional Intelligence and Leadership Emergence in Small Groups," Leadership Quarterly, 21 (3), 496-508.

Day, A. L., Therrien, D. L., and Carroll, S. A. (2005), "Predicting Psychological Health: 
Assessing the Incremental Validity of Emotional Intelligence beyond Personality, Type A Behavior, and Daily Hassles," European Journal of Personality, 19, 519-536.

Day, G. S. (1994), “The Capabilities of MarketDriven Organizations," Journal of Marketing, 58 (4), 37-52.

Di Mascio, R. (2010), "The Service Models of Frontline Employees," Journal of Marketing, $74(4), 63-80$.

Diaz, A. B. C., and Ruiz, F. J. M. (2002), "The Consumer's Reaction to Delays in Service," International Journal of Service Industry Management, 13 (2), 118-140.

Fornell, C., and Larcker, D. F. (1981), "Evaluating Structural Equation Models with Unobservable Variables and Measurement Error," Journal of Marketing Research, 18 (Feb), 39-50.

Franke, G. R., and Park, J. E. (2006), "Salesperson Adaptive Selling Behavior and Customer Orientation: A Meta-Analysis," Journal of Marketing Research, 43 (4), 693-702.

Glomb, T. M. and Tews, M. J. (2004), "Emotional Labor: A Conceptualization and Scale Development," Journal of Vocational Behavior, 64 (1), 1-23.

Gohm, C. L. (2004), "Moving forward with Emotional Intelligence," Psychological Inquiry, 15 (3), 222-227.

Goleman, D. (1995), Emotional Intelligence, New York: Bantam.

Grandey, A. A. (2000), "Emotion Regulation in the Workplace: A New Way to Conceptualize Emotional Labor," Journal of $\mathrm{Oc}^{-}$ cupational Health Psychology, 5 (1), 95110.

(2003), "When "the Show Must Go On": Surface and Deep Acting as Determinants of Emotional Exhaustion and Peer-Rated Service Delivery," Academy of Management Journal, 46 (1), 86-96.

Ha, Y. (2013), "The Executive of POSCO Energy Assaulted the Airline Crew, Making Public Apology, “ E-Today Newspaper, April, 22, 2013 (http://www.etoday.co.kr/news/section/ newsview.php?idxno $=721264$ ).

Hair, J., Anderson, R., Tatham, R., and Black, W. (2006), Multivariate Data Analysis, 6th ed., Englewood Cliffs, NJ: Prentice Hall. Hennig-Thurau, T., Groth, M., Paul, M., and Gremler, D. D. (2006), “Are All Smiles Created Equal? How Emotional Contagion and Emotional Labor Affect Service Relationships," Journal of Marketing, 70 (3), 58-73.

Hochschild, A. R. (1983), The Managed Heart: Commercialization of Human Feeling, Berkeley, CA: University of California Press. James, N. (1989), "Emotional Labor - Skill and Work in the Social Regulation of Feelings," Sociological Review, 37 (1), 15-42.

Johnson, H. A. M. and Spector, P. E. (2007), "Service with a Smile: Do Emotional Intelligence, Gender, and Autonomy Moderate the Emotional Labor Process?" Journal of 
Occupational Health Psychology, 12 (4), 319-333.

Jöreskog, K. and Sörbom, D. (1996), LISREL 8: User's Reference Guide, Chicago: Scientific Software International.

Kidwell, B., Hardesty, D. M., Murtha, B. R., and Sheng, S. B. (2011), "Emotional Intelligence in Marketing Exchanges," Journal of Marketing, 75 (1), 78-95.

Kim, S. H. (2010), "The Effect of Emotional Intelligence on Salesperson's Behavior and Customers' Perceived Service Quality," African Journal of Business Management, 4 (11), 2343-2353.

King, L. A., and Emmons, R. A. (1990), "Conflict over Emotional Expression - Psychological and Physical Correlates," Journal of Personality and Social Psychology, 58 (5), 864-877.

Ladhari, R. (2007), "The Effect of Consumption Emotions on Satisfaction and Word-ofMouth Communications," Psychology \& Marketing, 24 (12), 1085-1108.

Landy, F. J. (2005), "Some Historical and Scientific Issues Related to Research on Emotional Intelligence," Journal of Organizational Behavior, 26 (4), 411-424.

Lee, H. (2011), “The Influences of Emotional Intelligence and Emotional Labor on Job Burnout and Turnover Intention: Implications for HRD Practitioners," The Korean Journal of Human Resource Development Quarterly, 13 (4), 171-192.
Lee, I. G. and Ji, S. G. (2013), “A Study on the Role of Locomotion Orientation as an Antecedent of Salespeople' Selling Behavior," Asia Marketing Journal, 15 (2), 175-194. “

Liu, Y. M., Prati, L. M., Perrewe, P. L., and Ferris, G. R. (2008), "The Relationship between Emotional Resources and Emotional Labor: An Exploratory Study," Journal of Applied Social Psychology, 38 (10), 24102439.

Locke, E. A. (2005), "Why Emotional Intelligence Is An Invalid Concept," Journal of Organizational Behavior, 26 (4), 425-431.

Marks, R., Vorhies, D. W., and Badovick, G. J., (1996), “A Psychometric Evaluation of the ADAPTS Scale: A Critique and Recommendations," Journal of Personal Selling and Sales Management, 16 (4), 53-65.

Matthews, G., Zeidner, M., and Roberts, R. D. (2002), Emotional intelligence: Science and Myth, Boston: MIT Press.

Mayer, J. D. and Salovey, P. (1997), "What Is Emotional Intelligence?” In P. Salovey \& D. J. Sluyter, eds., Emotional Development and Emotional Intelligence: Implications for Educators, New York: Basic Books. Salovey, P., and Caruso, D. R. (2008), "Emotional Intelligence New Ability or Eclectic Traits?" American Psychologist, 63 (6), 503-517.

McColl-Kennedy, J. R., Patterson, P. G., Smith, A. K., and Brady, M. K. (2009), "Customer Rage Episodes: Emotions, Ex- 
pressions and Behaviors," Journal of Retailing, 85 (2), 222-237.

McMurrian, RC. A. (1996), "Social Cognitive Theory Model of Salesperson Performance," unpublished doctoral dissertation, The Louisiana State University.

Monaghan, D. M. (2006), ”Emotional Labor in Customer Service Work: The Perceived Difficulty and Dispositional Antecedents," unpublished doctoral dissertation, University of Akron, Akron, $\mathrm{OH}$.

Oatley, K. (2004), “Emotional Intelligence and the Intelligence of Emotions, Psychological Inquiry," 15 (3), 216-238.

Opengart, R. (2005), "Emotional Intelligence and Emotion Work: Examining Constructs From an Interdisciplinary Framework," Human Resource Development, 4 (1), 49-62.

Park, J. E. and Holloway B. B. (2003), “Adaptive Selling Behavior Revisited: An Empirical Examination of Learning Orientation, Sales Performance and Job Satisfaction," Journal of Personal Selling \& Sales Management, 23 (3), 239-251.

Ping, R. A. (1995), “A Parsimonious Estimating Technique for Interaction and Quadratic Latent Variables," Journal of Marketing Research, 32 (3), 336-347.

Podsakoff, P. M. and Organ, D. W. (1986), "Self- reports in Organizational Research: Problems and Prospects," Journal of $\mathrm{Ma}^{-}$ nagement, 12 (4), 531 - 544. MacKenzie, S. B., Lee,
J., and Podsakoff, N. P. (2003), "Common Method Biases in Behavioral research: A Critical Review of the Literature and $\mathrm{Re}^{-}$ commended Remarks," Journal of Applied Psychology, 88 (Oct), 879-903.

Preacher, K. K. and Hayes, A. F. (2008), "Asymptotic and Resampling Strategies for Addressing and Comparing Indirect Effects in Multiple Mediator Models," Behavior Research Methods, 40 (3), 879-891. Roman, S., and Iacobucci, D. (2010), "Antecedents and Consequences of Adaptive Selling Confidence and Behavior: A Dyadic Analysis of Salespeople and their Customers," Journal of the Academy of Marketing Science, 38 (3), 363-382.

Rozell, E. J., Pettijohn, C. E., and Parker, R. S. (2004), "Customer-Oriented Selling: Exploring the Roles of Emotional Intelligence and Organizational Commitment," Psychology \& Marketing, 21 (6), 405-424.

Saxe, R. and Weitz, B. A. (1982), "The SOCO Scale: A Measuring of the Customer Orientation of Salespeople," Journal of Marketing Research, 19 (2), 343-351.

Siguaw, J. A. J. (1991), “The Relationships of Customer Orientation, Adaptive Selling and Selected Antecedents: A Causal Model," unpublished doctoral dissertation, College of Administration and Business, Louisiana Tech University.

Sinkula, J. M. (1994), "Market-Information Processing and Organizational Learning," Journal 
of Marketing, 58 (1), 35-45.

Slaski, M. and Cartwright, S. (2002), "Health, Performance, and Emotional Intelligence: An Exploratory Study of Retail Managers," Stress and Health, 18 (2), 63-68. and Cartwright, S. (2003), "Emotional Intelligence Training and Its Implications for Stress, Health and Performance," Stress and Health, 19 (4), 233239.

Smith, A. K. and Bolton, R. N. (2002), "The Effect of Customers' Emotional Responses to Service Failures on their Recovery Effort Evaluations and Satisfaction Judgments," Journal of the Academy of Marketing Science, 30 (1), 5-23.

Spiro, R. L. and Weitz, B. A. (1990), "Adaptive Selling: Conceptualization, Measurement, and Nomological Validity," Journal of Marketing Research, 27 (1), 61-69.

Stock, R. M. and Hoyer, W. D. (2005), “An Attitude-Behavior Model of Salespeople's Customer Orientation," Journal of the Academy of Marketing Science, 33 (4), 536552.

Sujan, H. (1986), "Smarter versus Harder An Exploratory Attributional Analysis of Salespeople's Motivation," Journal of Marketing Research, 23 (1), 41-49.

, Weitz, B., and Kumar, N. (1994), "Learning Orientation, Working Smart and Effective Selling," Journal of Marketing, 58 (3), 39-52.
Totterdell, P. and Holman, D. (2003), "Emotion Regulation in Customer Service Roles: Testing a Model of Emotional Labor," Journal of Occupational Health Psychology, 8 (1), 55-73.

Tsaousis, I. and Nikolaou, I. (2005), "Exploring the Relationship of Emotional Intelligence with Physical and Psychological Health Functioning," Stress and Health, 21 (2), 77-86.

Weitz, B. A., Sujan, H., and Sujan, M. (1986), "Knowledge, Motivation, and Adaptive Behavior: A Framework for Improving Selling Effectiveness," Journal of Marketing, 50 (Oct), 174-191.

Wirtz, J. and Bateson, J. E. G. (1999), "Consumer Satisfaction with Services: Integrating the Environment Perspective in Services Marketing into the Traditional Disconfirmation Paradigm," Journal of Business Research, 44 (1), 55-66.

Wong, A. (2005), "Affective Service Display and Customer Mood," Journal of Service Research, 8 (2), 117-130.

Wong, C. and Law, K. S. (2002), “The Effects of Leader and Follower Emotional Intelligence on Performance and Attitude: An Exploratory Study," The Leadership Quarterly, 13 (3), 243-274. 


\section{〈Appendix〉 Final Measurement Items}

Emotional Intelligence (Wong and Law, 2002)

Self-emotion appraisal (4 items)

- have a good sense of why I have certain feelings most of the time

- have good understanding of my own emotions

- really understand what I feel

- always know whether or not I am happy

Others' emotion appraisal (4 items)

- always know my friends' emotion from their behavior

- a good observer of others' emotions

- sensitive to the feelings and emotions of others

- have good understanding of the emotions of people around me

Use of emotion (4 items)

- always set goals for myself and then try my best to achieve them

- always tell myself I am a competent person

- a self-motivated person

- always encourage myself to try my best

Regulation of emotion (4 items)

- able to control my temper and handle difficulties rationally

- quite capable of controlling my own emotions

- always calm down quickly when I am very angry

- have good control of my own emotions

Emotional labor (Brotheridge and Lee, 2003; Kim and Han, 2008)

Deep acting (3 items)

- make an effort to actually feel the emotions that I have to display to others

- try to actually experience the emotions that I must show

- express emotions that need to be revealed through actual feelings in relationship with customers

Surface acting (3 items)

- pretend to have emotions that I don't really have

- hide my true feelings about a situation

- work required by the fact that I feel the mood and emotion is often different from

Customer orientation (Saxe and Weitz, 1982)

- try to get customers to discuss their needs with me

- willing to disagree with a customer in order to help him make a better decision

- try to give customers an accurate expectation of what the product will do for them

- answer a customer's questions about products or services as correctly as I can

- try to bring a customer with a problem together with a product/service that helps him/her solve that problem

- try to achieve my goals by satisfying customers

- try to find out what kind of product / service would be most helpful to a customer

ASB (Spiro and Weitz, 1990; Park and Holloway, 2003)

- very flexible in the selling approach he / she use

- easily use a wide variety of selling approaches

- do not use a set sales approach

- vary my sales style from situation to situation

- treat all of my buyers pretty much differently

- experiment with different sales approaches

- changing his / her approach from one customer to another 